Review article

\title{
Lacosamide as monotherapy in focal seizure: Literature review
}

\author{
Kishore R. Sonkusare*, Hanmant V. Barkate \\ Department of Medical Affairs, Intas Pharmaceuticals Ltd., Ahmedabad, Gujarat, India
}

\section{A R T I C L E I N F O}

\section{Article history:}

Received 27 June 2016

Accepted 21 December 2016

Available online 12 January 2017

\section{Key words:}

Lacosamide

Monotherapy

Historical controlled trial

Focal seizure

\begin{abstract}
A B S T R A C T
Lacosamide is a newer approved antiepileptic drug (AED) characterized by its novel pharmacodynamic profile. It is now approved by United States Food and Drug Administration for use as monotherapy in adults (aged $>17$ years) with focal seizures based on historical controlled trial by Wechsler RT et al in 2014. Randomized controlled trials on lacosamide monotherapy have demonstrated significant reduction in median seizure frequency. In addition, 50\% responder rates for lacosamide was noted in half of the patients, with retention rate in two third of patients in 1 year follow up period. Adverse events reported in clinical trials were mostly mild to moderate in intensity. The most common adverse events were dizziness, headache, convulsion, nausea and fatigue while convulsion and dizziness were commonly responsible for drug discontinuation. Overall, lacosamide monotherapy can be a good treatment option in patients with focal seizure.
\end{abstract}

@ 2016 Indian Epilepsy Society. Published by Elsevier, a division of RELX India, Pvt. Ltd. All rights reserved.

\section{Contents}

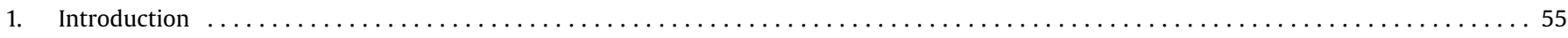

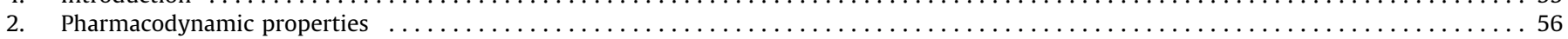

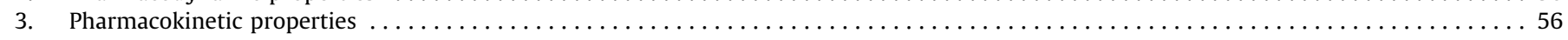

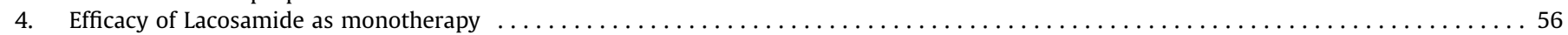

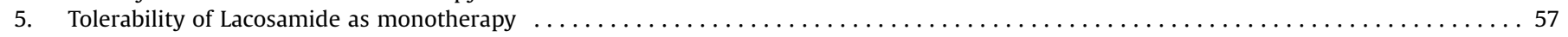

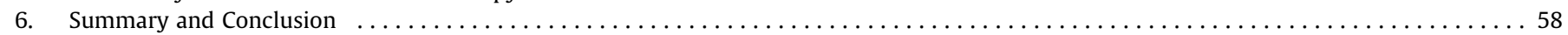

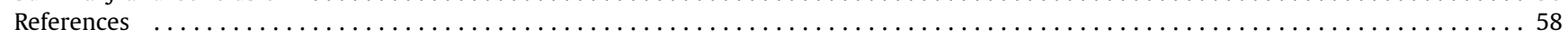

\section{Introduction}

Epilepsy is a brain disorder defined by at least two unprovoked (or reflex) seizures occurring $>24 \mathrm{~h}$ apart and one unprovoked seizure and a probability of further seizures in next 10 years. Epilepsy is clinically presented as recurrent seizures due to abnormal synchronous or excessive neuronal discharge in the brain. ${ }^{1}$ Seizures are classified as generalized seizures (synchronized discharges involving both hemispheres), or focal seizures (previously called partial-onset seizures) involving one cerebral hemisphere. ${ }^{2}$ The worldwide prevalence of epilepsy is between 4 and 10 per 1000 population, ${ }^{3}$ while in India it is 5.59 per 1000

\footnotetext{
* Corresponding author at: Intas Pharmaceuticals Ltd. Premier House 1, Off Gurudwara, SG Highway Bodakdev, Ahmedabad 380054, India.

E-mail address: kishore_sonkusare@intaspharma.com (K.R. Sonkusare).
}

population with equally distributed between men and women or urban and rural region. ${ }^{4}$

The goal of pharmacotherapy with antiepileptic drugs (AEDs) is to reduce the frequency of epileptic seizures and achieve a seizurefree state. ${ }^{5}$ There are evidences that the majority of seizure patients can achieve seizure freedom with monotherapy, but only four AEDs i.e. felbamate, lamotrigine, oxcarbazepine, and topiramate are being approved by United States Food and Drug Administration (USFDA) as monotherapy, and only topiramate and oxcarbazepine have an indication for initial monotherapy. ${ }^{6-9}$ Another 4 drugs have been considered as conversion to monotherapy in U.S.: lamotrigine extended-release, levetiracetam extended-release, pregabalin and eslicarbazepine. ${ }^{10-13}$

Lacosamide (R-enantiomer of 2-acetamido- $N$-benzyl-3methoxypropionamide, previously known as harkoseride or ADD 234037) is a newer approved AED characterized by his novel pharmacodynamic profile. ${ }^{14}$ Lacosamide (LCM) was approved in 2008 by the European Medicines Agency (EMEA) ${ }^{15}$ and by the US 
FDA $^{16}$ as adjunctive treatment in patient aged $>16$ years (EMEA) and 17 years (FDA) with focal seizures with or without generalization and is newly licensed in 2014 by US FDA $^{16}$ for use as monotherapy in adults (aged $>17$ years) with focal seizures. Oral lacosamide is available in 50,100,150 and 200-mg in tablet form and $10 \mathrm{mg} / \mathrm{ml}$ in oral solution. An intravenous formulation $(10 \mathrm{mg} /$ $\mathrm{ml}$ ) is also available for short-term replacement of oral LCM but it is not currently approved for status epilepticus (SE). ${ }^{16}$

This article reviews the therapeutic use of lacosamide as monotherapy in patients with focal seizures along with an overview of its novel pharmacological properties.

\section{Pharmacodynamic properties}

The specific mechanism by which LCM exerts its antiepileptic effects in humans is not yet known. ${ }^{16}$ Recent study results suggest that LCM has a dual mode of action responsible for its anticonvulsant and analgesic activity. ${ }^{14}$ LCM has an effect on the voltage-gated sodium channels (VGSCs). LCM has unique ability to with the slow inactivation of VGSCs with no role in fast inactivation, unlike other AEDs, such as carbamazepine, phenytoin and lamotrigine inhibit both slow and fast inactivation of VGSCs. ${ }^{17}$ This enhancement of slow inactivation of sodium channels controls neuronal hyperexcitability by normalizing activation thresholds and decreasing pathophysiological neuronal activity. ${ }^{18}$

Lacosamide also exerts its action by binding to collapsingresponse mediator protein-2 (CRMP2), a phosphoprotein that is involved in neuronal differentiation and control of axonal growth. ${ }^{19,20}$ However, this binding has recently been debated as in vitro study has advocated that LCM does not specifically bind to CRMP-2. ${ }^{21}$

\section{Pharmacokinetic properties}

Following oral administration, LCM is rapidly and completely absorbed after single dose with negligible first pass effect with absolute bioavailability $\sim 100 \%$. Maximum LCM serum concentration is attained in 1-4hours after oral administration and immediately after intravenous infusion. There is no effect of food on the rate and extent of absorption. Steady-state plasma levels $\left(C_{s s}\right)$ are achieved after 3 days of twice daily oral administration. The plasma concentration of LCM shows linear and proportional increase with increasing oral and intravenous doses up to 800 and $300 \mathrm{mg}$, respectively, with low inter- and intra-subject variability. Intravenous infusion of LCM $200 \mathrm{mg}$ is bioequivalent to the same dose administered orally in healthy volunteers. A single oral dose of $200 \mathrm{mg}$ approximates steady-state concentrations which is comparable to the oral dose of $100 \mathrm{mg}$ twice a day. ${ }^{16,20,22,23}$

Lacosamide exhibits negligible plasma protein binding $(<15 \%)$ and has a volume of distribution $(\sim 0.6 \mathrm{~L} / \mathrm{kg})$ equal to total body water. LCM is mainly excreted from the systemic circulation by kidney and biotransformation. After oral and intravenous administration, approximately $95 \%$ of radioactivity administered is excreted in the urine mainly as unchanged lacosamide ( $\sim 40 \%$ of the dose), its O-desmethyl metabolite $(\sim 30 \%)$, and $\sim 20 \%$ as a structurally unknown polar fraction and small amount $(<0.5 \%)$ in the feces. CYP3A4, CYP2C9, and CYP2C19 isoforms are mainly involved in the metabolism of O-desmethyl metabolite. The elimination half-life of the unchanged lacosamide is $\sim 13 \mathrm{~h}$ and its 0 -desmethyl metabolite is $15-23$ hours. Elimination is not altered by any type of dosing, multiple dosing or intravenous administration. ${ }^{16,20,22,23}$

Lacosamide has shown no pharmacokinetic differences in special population like age ( $>65$ years), gender, race or CYP2C19 polymorphism. ${ }^{16}$ There is no clinically significant drug-drug interaction of lacosamide with commonly used AEDs like valproic acid, carbamazepine, gabapentin, levetiracetam, phenytoin) and drugs that undergo CYP-mediated biotransformation like warfarin, midazolam, omeprazole (Table 1 ). ${ }^{22}$

\section{Efficacy of Lacosamide as monotherapy}

Lacosamide has been approved for monotherapy by the US FDA based on historical controlled trial by Wechsler RT et al. ${ }^{24}$ in 2014 and its efficacy as monotherapy has been established in prospective, ${ }^{25}$ retrospective study ${ }^{26}$ each and data presented in abstract format at the conference. ${ }^{27-29}$

The efficacy of conversion from stable dosages of 1-2 AEDs to oral lacosamide monotherapy was evaluated in patients (age 16-70 years) in a historical-cohort controlled, double-blind study [ALEXMT] (A Lacosamide EXchange to Monotherapy Trial) conducted by Wechsler et al. ${ }^{24}$. Those patients experiencing 2-40 focal seizures per 28 days during the 8 -week prospective baseline were eligible for randomization to lacosamide $400(n=319)$ or $300 \mathrm{mg} /$ day in $3: 1$ proportion. A $300 \mathrm{mg} /$ day treatment group $(n=106)$ was included to blind treatment group ( $400 \mathrm{mg} / \mathrm{day}$ ). Study was conducted in two phases: 3 week titration phase and 16 week lacosamide maintenance phase ( 6 week withdrawal phase in which background AEDs has been withdrawn and 10 week monotherapy phase). The primary efficacy outcome was the percentage of patients receiving lacosamide $400 \mathrm{mg} /$ day who met $\geq 1$ of the exit criteria (Table 2) by day 112 of the maintenance phase in the full analysis set $(n=284$; i.e. patients who completed the titration phase and initiated withdrawal phase) compared with the prespecified historical-control exit percentage (65.3\%). Analyses were done by using Kaplan-Meier estimates.

By day 112, the percentage of patients in the lacosamide $400 \mathrm{mg} /$ day monotherapy group meeting at least one exit criterion was $30.0 \%$ (95\% CI 24.6-35.5\%) which was superior than historical control, as the upper limit of the $95 \%$ confidence interval was lower than the historical-control exit percentage (35.5\% versus $65.3 \%$ ). The mean time to exit due to meeting at least one exit criterion during maintenance phase was 45.0 days in the lacosamide $400 \mathrm{mg} /$ day monotherapy group. Median duration of lacosamide monotherapy $400 \mathrm{mg} /$ day treatment was 71 days during maintenance phase. In addition, Patient's Global Impression of Change

Table 1

Main characteristics and pharmacokinetic properties of lacosamide. ${ }^{20}$

\begin{tabular}{|c|c|}
\hline Absolute bioavailability & $100 \%$ \\
\hline $\mathrm{T}_{\max }$ & $1-4 \mathrm{~h}$ \\
\hline $\mathrm{C}_{\max }$ & $8.7 \pm 1.8 \mu \mathrm{g} / \mathrm{ml}$ \\
\hline Elimination $t_{1 / 2}$ & $13 \mathrm{~h}$ \\
\hline Plasma protein binding & $15 \%$ \\
\hline Volume of distribution & $0.6 \mathrm{~L} / \mathrm{kg}$ \\
\hline Effect of food on absorption & No \\
\hline Route of elimination & Renal \\
\hline Significant drug interaction with other antiepileptic drugs or with warfarin, midazolam, metformin, omeprazole, digoxin, estrogen & No \\
\hline Dose conversion from oral to intravenous or vice versa & No \\
\hline
\end{tabular}


Table 2

Predefined exit criteria. ${ }^{24}$

\begin{tabular}{|c|c|}
\hline 1. & $A \geq 2$ fold increase in average 28 - day focal seizure frequency compared to baseline phase \\
\hline 2. & $A \geq 2$ fold increase in consecutive 2 -day focal seizure frequency compared to highest consecutive 2-day focal seizure frequency during baseline phase \\
\hline 3. & Occurrence of one generalized tonic-clonic seizure if none had occurred in past 6 months since randomization. \\
\hline 4. & Prolongation or worsening of overall seizure frequency, duration, type, or pattern as serious enough to necessitate discontinuation from the study. \\
\hline 5. & Status epilepticus or new onset of serial or cluster seizures. \\
\hline
\end{tabular}

(PGIC) \& Clinical Global Impression of Change (CGIC) showed some improvement in $74.3 \%$ and $75.4 \%$ patients respectively receiving $400 \mathrm{mg} /$ day. Similar improvement was noted in lacosamide $300 \mathrm{mg} /$ day group $\left(72.7 \%\right.$ in both scales). ${ }^{24}$

In post hoc analysis of lacosamide $400 \mathrm{mg} /$ day monotherapy group, $\geq 50 \%, \geq 75 \%$ \& $100 \%$ reductions in seizure frequency during monotherapy maintenance phase were seen in $60.7,34.3$ and $14.9 \%$ patients respectively. ${ }^{24}$

In another post hoc analysis presented in 68th Annual Meeting of the American Epilepsy Society, ${ }^{27}$ conversion monotherapy to lacosamide was found effective in both $300 \mathrm{mg}$ and $400 \mathrm{mg} /$ day group. $\geq 50 \%$ reduction in seizure frequency/28 days was seen in 50,42 and $39 \%$ in patients with $0-5(n=100),>5-15(n=120)$ and 15 years $(n=205)$ duration of epilepsy respectively while seizurefree rates was noted in respective 12,12 and $6 \%$ patients during 10 weeks monotherapy phase. During monotherapy phase in patients previously discontinued $0,1,2$ or $\geq$ AEDs before study entry $(n=85$, 72,73 and 195 , respectively), $\geq 50 \%$ responder rates were noted in $45,42,49$ and $39 \%$ patients respectively, and respective seizurefree rates were $13,14,6$ and $7 \%{ }^{27}$

The median focal seizure frequency per 28 days during the baseline phase decreased during lacosamide maintenance phase by $51 \%$ (simple seizure) and $60 \%$ (complex seizure) for all seizures. ${ }^{28}$ This post-hoc analysis suggested that seizure frequency across all patients was reduced during titration and was maintained during withdrawal of background AEDs and LCM monotherapy maintenance for all seizure types. ${ }^{28}$

In a prospective study conducted by Lattanzi $S$ et al. ${ }^{25}$, lacosamide as conversion monotherapy was evaluated for 1 year in patients with focal seizure. Patients who achieved 1 year seizure freedom on lacosamide add-on therapy, then converted to lacosamide monotherapy (350-400 mg/day) were followed up for 1 year $(n=58)$. Primary outcome parameters were the seizure freedom at 1 year as monotherapy from withdrawal of background AED and the retention rate of lacosamide as single AED. Seizure freedom under lacosamide monotherapy was noted in $55.2 \%$ patients, $\geq 75 \%$ reduction in seizure frequency in $8.6 \%$ patients. Seizure freedom was maintained in $69.2 \%$ and $26.3 \%$ patients with 1-2 and $\geq 3$ previous treatments, respectively. Retention rate of lacosamide as monotherapy was $63.8 \%$.
One retrospective study conducted by Giráldez BG et al. ${ }^{26}$ has evaluated efficacy and tolerability in patients with focal seizure on lacosamide monotherapy (mean dose $252.7 \mathrm{mg} /$ day). Patients were divided in 2 groups: Group 1 - naive to AED therapy $(\mathrm{n}=18)$ and Group 2- previously been treated with AEDs $(n=48)$. Seizure-free rates and mean seizure frequency reduction were analyzed during complete follow up and after 6 and 12 months of stable maintenance dose. Mean duration of monotherapy was 15.5 months. Overall seizure free rate was seen in $63.6 \%$ (72.2\% in Group $1 \& 60.4 \%$ in Group 2 ) while the seizurefreedom at 6 and 12 months follow up were $77.6 \%$ and $72.3 \%$ respectively. Mean seizure frequency reduction seen in the both group was $74.8 \%$ and $75.6 \%$ at 6 and 12 months respectively $(\mathrm{p}<0.001)$.

Durgin et al. $^{29}$ explored the real-world characteristics of patients with epilepsy treated with LCM monotherapy in which patients were switching from lacosamide as adjuvant therapy (41.2\%) or from other AED as monotherapy (37.4\%) and AED treatment-naïve $(18.5 \%)$, based on a large $(n=746)$ data retrieved from the IMS Phar Metrics Plus health claims database. Retention rate with LCM monotherapy was $69.8 \%$ during 1 year follow up period.

Overall efficacy of lacosamide as monotherapy is good in focal seizure patients with responder rate $(\geq 50 \%$ reduction in seizure frequency/28 days) up to $60 \%$ and total freedom from seizure was seen 12-63\% patients. More than two third patients retained lacosamide as monotherapy during 1 year follow up (Table 3 ).

\section{Tolerability of Lacosamide as monotherapy}

Lacosamide monotherapy was generally well tolerated in patients with focal seizure, with the majority of adverse events reported were mild or moderate in intensity. In historical controlled study ${ }^{24}$ treatment emergent adverse events (TEAE) was noted in $84.5 \%$ patients, mostly seen during titration phase out of which $16.9 \%$ patients discontinued the lacosamide therapy due to TEAE. Serious adverse events were reported in $4 \%$ patients, which were mainly unrelated to lacosamide therapy; convulsion was the only serious adverse effect occurred in more than 1 patient $\left(\mathrm{n}=5\right.$ patients). ${ }^{24}$ The most common adverse events noted in various clinical trials were dizziness followed by headache, nausea,

Table 3

Comparison of responder rate $\&$ seizure freedom rate in various trials. ${ }^{24-27}$

\begin{tabular}{|c|c|c|c|c|}
\hline Parameters & Wechsler RT & Ryvlin P & Lattanzi S & Giráldez BG \\
\hline No. of patients & $\begin{array}{l}\text { LCM } 400 \mathrm{mg}(\mathrm{n}=319) \\
\& 300 \mathrm{mg}(\mathrm{n}=106)\end{array}$ & LCM $400 \& 300 \mathrm{mg}(\mathrm{n}=425)$ & $\begin{array}{l}\text { LCM } \\
400 \mathrm{mg} \\
(\mathrm{n}=58)\end{array}$ & $\begin{array}{l}\text { LCM } \\
400 \mathrm{mg} \\
(\mathrm{n}=114)\end{array}$ \\
\hline $\begin{array}{l}\geq 50 \% \text { reduction in seizure } \\
\text { frequency (\% patients) }\end{array}$ & $60.7 \%$ & $\begin{array}{l}\text { - } 50 \% \text { with } 0-5 \text { years }^{a} \\
\text { - } 42 \% \text { with } 5-15 \text { years }^{a} \\
\text { - } 39 \% \text { with }>15 \text { years }^{a}\end{array}$ & - & - \\
\hline $\begin{array}{l}\text { Seizure freedom (\% } \\
\text { patients) }\end{array}$ & $14.9 \%$ & $\begin{array}{l}\text { - } 12 \% \text { with } 0-5 \text { years }^{\mathrm{a}} \\
\text { - } 12 \% \text { with } 5-15 \text { years }^{\mathrm{a}} \\
\text { - } 6 \% \text { with }>15 \text { years }^{\mathrm{a}}\end{array}$ & $55.2 \%$ & $63.6 \%$ \\
\hline
\end{tabular}

a Patients with total duration on epilepsy (years). 
convulsion, somnolence, and fatigue. The most common TEAEs which lead to discontinuation of lacosamide monotherapy were convulsion, dizziness and fatigue. ${ }^{24-26,28}$

\section{Summary and Conclusion}

Lacosamide is a novel AED that has been approved as monotherapy in patients of 17 years of age or older with focal seizures with or without secondary generalization in 2014. Lacosamide has a favorable pharmacokinetic profile that includes a relatively long half-life $(13 \mathrm{~h})$ which allows for twice-daily administration; has very low plasma protein binding (15\%), 100\% bioavailability that is not affected by concomitant food, little potential for significant drug-drug interactions and easy switch over from oral to intravenous therapy for short-term at the same dosage and vice versa, which may be mainly helpful in situations where oral therapy is not suitable.

With respect to efficacy, historical controlled study has demonstrated superiority to that of a historical-control cohort converting from previous AED therapy. Several prospective and retrospective studies confirmed the efficacy of lacosamide for focal seizure control with retention rate was seen in more than two third patients during 1 year follow up period.

Lacosamide was well tolerated. Dizziness was the most common adverse event ( $\mathrm{AE}$ ), followed by headache, nausea, convulsion and fatigue. All these AEs were reported during titration phase and were of mild to moderate intensity. Convulsion and dizziness were commonly responsible for drug discontinuation.

In conclusion, with good pharmacokinetic profile of lacosamide, proven efficacy and good tolerability as monotherapy, lacosamide can be a useful and welcome addition to the existing therapy of focal seizure.

\section{References}

1. Fisher RS, Acevedo C, Arzimanoglou A, et al. ILAE official report: a practical clinical definition of epilepsy. Epilepsia. 2014;55(April (4)):475-482.

2. Berg AT, Berkovic SF, Brodie MJ, et al. Revised terminology and concepts for organization of seizures and epilepsies: report of the ILAE commission on classification and terminology, 2005-2009. Epilepsia. 2010;51(April (4)):676685.

3. de Boer HM, Mula M, Sander JW. The global burden and stigma of epilepsy. Epilepsy Behav. 2008;12(May (4)):540-546.

4. Bharucha NE. Epidemiology of epilepsy in India. Epilepsia. 2003;44(s1):9-11.

5. Shneker BF, Fountain NB. Epilepsy Dis Mon. 2003:49(July (7)):426-478.

6. Felbatol (felbamate). US prescribing information. Somerset, NJ: MEDA Pharmaceuticals Inc., 2012 [Internet]. [cited 2016 Mar 21]. Available from: http://www.accessdata.fda.gov/drugsatfda_docs/label/2009/020189s022lbl. pdf.

7. Lamictal (lamotrigine). Summary of product characteristics. Uxbridge, Middlesex, UK: GlaxoSmithKline UK, 2013. [Internet]. [cited 2016 Mar 21]. Available from: http:/www.fda.gov/downloads/AdvisoryCommittees/ CommitteesMeetingMaterials/PediatricAdvisoryCommittee/UCM235547.pdf.

8. Trileptal (oxcarbazepine). Summary of product characteristics. Camberley, Surrey, UK: Novartis Pharmaceuticals UK Ltd, 2013. [Internet]. [cited 2016 Mar 21]. Available from: http://www.accessdata.fda.gov/drugsatfda_docs/label/ 2009/021014s026,021285s021lbl.pdf.

9. Topamax (topiramate). US prescribing information. Titusville, NJ: OrthoMcNeil Neurologics, Division of Ortho-McNeil-Janssen Pharmaceuticals, Inc.;
2013. [Internet]. [cited 2016 Mar 21]. Available from: http://www.accessdata. fda.gov/drugsatfda_docs/label/2009/020505s038s039,020844s032s034lbl. pdf.

10. French JA, Temkin NR, Shneker BF, et al. Conversion to monotherapy: first study using a historical control group. Neurotherapeutics. 2012;9(January (1)):176-184.

11. Chung S, Ceja H, Gawłowicz J, et al. Levetiracetam extended release conversion to monotherapy for the treatment of patients with partial-onset seizures: a double-blind, randomised, multicentre, historical control study. Epilepsy Res. 2012;101(August (1-2)):92-102.

12. French J, Kwan P, Fakhoury T, et al. Pregabalin monotherapy in patients with partial-onset seizures: a historical-controlled trial. Neurology. 2014;82 (February (7)):590-597.

13. Sperling MR, Harvey J, Grinnell T, Cheng H, Blum D, the 045 Study Team. Efficacy and safety of conversion to monotherapy with eslicarbazepine acetate in adults with uncontrolled partial-onset seizures: a randomized historicalcontrol phase III study based in North America. Epilepsia. 2015;56(April (4)):546-555.

14. Beyreuther BK, Freitag J, Heers C, Krebsfänger N, Scharfenecker U, Stöhr T. Lacosamide a review of preclinical properties. CNS Drug Rev. 2007;13(1):2142.

15. European Medicines Agency. Lacosamide: summary of product characteristics. [Internet]. [cited 2016 Mar 22]. Available from: http://www.ema.europa.eu/ docs/en_GB/document_library/EPAR_-_Product_Information/human/ 000863/WC500050338.pdf.

16. US FDA. Vimpat (lacosamide): highlights of prescribing information. [Internet]. [cited 2016 Mar 22]. Available from: http://www.vimpat.com/ PDF/vimpat_PI.pdf.

17. Curia G, Biagini G, Perucca E, Avoli M. Lacosamide. CNS Drugs. 2009;23(7):555568.

18. Doty P, Rudd GD, Stoehr T, Thomas D. Lacosamide. Neurotherapeutics. 2007;4 (1):145-148.

19. de Biase S, Gigli GL, Valente M, Merlino G. Lacosamide for the treatment of epilepsy. Expert Opin Drug Metab Toxicol. 2014;10(March (3)):459-468.

20. Kellinghaus C. Lacosamide as treatment for partial epilepsy: mechanisms of action, pharmacology, effects, and safety. Ther Clin Risk Manag. 2009;5:757766.

21. Wolff C, Carrington B, Varrin-Doyer M, et al. Drug binding assays do not reveal specific binding of lacosamide to collapsin response mediator protein 2 (CRMP-2): no specific binding of lacosamide to CRMP-2. CNS Neurosci Ther. 2012;18(June (6)):493-500.

22. Scott LJ. Lacosamide a review in focal seizures in patients with epilepsy. Drugs. 2015;75(December (18)):2143-2154.

23. Beydoun A, D'souza J, Hebert D, Lacosamide Doty P. pharmacology, mechanisms of action and pooled efficacy and safety data in partial-onset seizures. Expert Rev Neurother. 2009;9(January (1)):33-42.

24. Wechsler RT, Li G, French J, et al. Conversion to lacosamide monotherapy in the treatment of focal epilepsy: Results from a historical-controlled, multicenter double-blind study. Epilepsia. 2014;55(July (7)):1088-1098.

25. Lattanzi S, Cagnetti C, Foschi N, Provinciali L, Silvestrini M. Lacosamide monotherapy for partial onset seizures. Seizure. 2015;27(April):71-74.

26. Giráldez BG, Toledano R, García-Morales I, et al. Long-term efficacy and safety of lacosamide monotherapy in the treatment of partial-onset seizures: a multicenter evaluation. Seizure. 2015;29(July):119-122.

27. Ryvlin P, Sperling M, Chung S, et al. Conversion to lacosamide monotherapy: post hoc analysis on responder and seizure freedom rates [abstract no 3.292] 68th Annual Meeting of the American Epilepsy Society. 2014; [Internet]. [cited 2016 Mar 25]. Available from: https://www.aesnet.org/meetings_events/ annual_meeting_abstracts/view/1868740.

28. Stern J, Sperling M, Chung S, et al. Focal seizure frequency by study phase and seizure type in conversion to lacosamide monotherapy study: a post hoc analysis [abstract no 3.291]. 68th Annual Meeting of the American Epilepsy Society. 2014; [Internet]. [cited 2016 Mar 23]. Available from: https://www. aesnet.org/meetings_events/annual_meeting_abstracts/view/1868739.

29. Durgin T, Wade R, Chen C-C, et al. Lacosamide monotherapy treatment pathways in epilepsy patients in a US managed care population [abstract no 2.297]. 68th Annual Meeting of the American Epilepsy Society. 2014; [Internet]. [cited 2016 Mar 25]. Available from: https://www.aesnet.org/ meetings_events/annual_meeting_abstracts/view/1868379. 